***CITE AS: Konrath, S. \& Tian, Y. (2017, in press) Narcissism and prosocial behavior. Hermann, T., Brunell, A., \& Foster, J. (Eds.) Handbook of Trait Narcissism: Key Advances, Research Methods, and Controversies. New York: Springer.***

\title{
Narcissism and prosocial behavior
}

Sara Konrath \& Yuan Tian

Keywords: prosocial behavior; extended agency model; volunteering; helping; giving; charitable donations; organizational citizenship behavior 
There are different types of narcissism, and the current chapter primarily reviews the relationship between grandiose narcissism and prosocial behavior. Unless specified otherwise, the term narcissism refers to grandiose narcissism, which is a personality trait that involves inflated self-esteem, a need for admiration, and low empathy (Miller \& Campbell, 2008). A large body of research examines narcissism and interpersonal relationships. For example, although they make positive first impressions (Paulhus, 1998), they have trouble with longer-term relationships (Campbell \& Foster, 2002; Paulhus, 1998). In addition, narcissistic people tend to behave aggressively, especially after being insulted or rejected (Bushman \& Baumeister, 1998; Konrath, Bushman, \& Campbell, 2006).

Yet, there is comparatively little research on narcissism and prosocial behavior, or actions intended to benefit others (Batson \& Powell, 2003). Perhaps scholars assume that narcissists' lower empathy (Hepper, Hart, \& Sedikides, 2014; Watson, Grisham, Trotter, \& Biderman, 1984), which is a key predictor of prosocial behavior (Batson, 2011; Fengqin \& Zhaohui, 2016), implies that they will behave less prosocially overall. Or, they may assume that more antisocial behavior among narcissistic people implies less prosocial behavior. However, there are many motivations for prosocial behavior, some more altruistic and some more egoistic (Batson, 2011; Batson \& Powell, 2003). We posit that more narcissistic people may perform prosocial acts strategically, for example, to improve their reputations or to receive something in return.

The Extended Agency Model can guide predictions about narcissism and prosocial behavior (Campbell \& Foster, 2007). In this model, more narcissistic people are seen as being especially motivated by rewards from agentic experiences, for example, those involving high status and power. They are also less motivated by rewards from communal sources, such as close relationships with others. This combination of high agency and low communion leads narcissistic people to seek power, status, success, and attention, in order to gain narcissistic esteem (e.g. feelings of pride, self-esteem, and dominance), while simultaneously avoiding developing deep caring social relationships.

Thus, when narcissistic people behave prosocially, we posit that they may do so only after strategically attending to the potential costs and benefits, rather than making more emotionally-driven or automatic decisions (Zaki \& Mitchell, 2013). Narcissistic people could strategically adjust the cost-benefit ratio of giving by lowering the cost side of the equation. For example, they may engage in prosocial activities that are easy, quick, and involve one-time commitments. So-called "slackitivism" acts such as sharing messages or liking posts on social media are perfect examples of this (Kristofferson, White, \& Peloza, 2014).

They could also increase the benefit side of the equation by only helping when benefits or rewards to themselves are obvious. Different kinds of benefits or rewards that can accrue from acting prosocially include tangible benefits, like free stickers or other small gifts often given by charities to increase donation behavior (Newman \& Shen, 2012) or like gifts giving in close relationships (Carrier, 1991). However, there can also be intangible benefits, such as an increased reputation, receiving attention, or increasing recipients' sense of obligation to return favors. Overall, although many people give to and help others because they care about fulfilling others' needs (an altruistic motivation), the Extended Agency Model suggests that narcissistic people may be less intrinsically motivated by such concerns.

\section{Summary of key advancements: What do we know?}

We next review the research literature to date on grandiose narcissism and prosocial behavior, interpreting it in light of the Extended Agency Model. Some prosocial behavior occurs 
within the context of formal, organizational settings such as nonprofit organizations (e.g. donating money, volunteering) or workplaces (e.g. organizational citizenship behaviors). Others are more informal, and occur as part of our daily lives, while interacting with friends, relatives, and even strangers. Across these contexts, prosocial behaviors can range from more spontaneous to more planned acts, more casual to more serious acts, more direct versus more indirect acts, and more emotional versus more practical types of support (McGuire, 1994; Pearce \& Amato, 1980; Smithson \& Amato, 1982). Although research on narcissism and prosocial behavior is only in its infancy, it already has wide coverage across formal and informal prosocial behaviors, and across a number of these other dimensions.

\section{Volunteering for nonprofit organizations}

\section{Formal prosocial behaviors}

In 2015, 24.9\% of Americans donated their time to nonprofit organizations ("Corporation for National \& Community Service," 2017). Although narcissism is unrelated to the propensity to volunteer (Kauten \& Barry, 2016; Konrath, Ho, \& Zarins, 2016), this may be because people volunteer for many reasons, some of which are more altruistic, and some of which involve receiving personal benefits (Clary \& Snyder, 1999; Clary et al., 1998). Theoretically, narcissistic people should have less altruistic, and more self-oriented, reasons for volunteering.

However, there are some inconsistent results. Of three known studies on this topic, two found that narcissistic adults have less altruistic motives for volunteering (Brunell, Tumblin, \& Buelow, 2014; Konrath et al., 2016). However, another study found no such relationship among college students (Brunell et al, 2014, Study 2). Of the three studies, two found that narcissistic people volunteer because it's important to others, a social motive for volunteering (Brunell et al, 2014). Two studies also found a positive association between narcissism and volunteering to enhance one's career (Brunell et al, 2014). There have been inconsistent relationships between narcissism and two other motives: desiring to learn more (understanding motive) and desiring to protect oneself (protective motive; Brunell et al, 2014; Konrath et al, 2016). And oddly, no study has found that narcissists volunteer to enhance their self-esteem (enhancement motive).

Overall, the results generally support the Extended Agency Model, which would predict that narcissism is associated with less altruistic, and more self-focused, motives for volunteering. However, the inconsistent results warrant further research attention.

\section{Charitable donations}

Americans donated \$373.25 billion to charity in 2015 (O'Brien, 2017). Yet there is only one known study on the topic of narcissism and charitable donations (Konrath et al., 2016). In line with our theorizing about narcissism and 'slacktivism,' this study found that during a social media campaign to raise funds for ALS (the "ice bucket challenge"), narcissistic people were more likely to post a video of themselves pouring ice water on their heads, and were less likely to actually make a donation to the cause. We think this is because posting a video online allowed narcissistic people to get attention, without the actual cost of the donation.

This area is rich for future studies. For example, since narcissistic people struggle to feel empathy (Hepper et al., 2014), would they be less likely to donate to basic needs charities, such as homeless shelters or food banks? Would they be more likely to make designated gifts, that are under their control, versus unrestricted gifts, in which the organization can use the money however it's most needed? Would they be more likely to donate to charities in the presence of tangible (e.g. free gifts with donation) or intangible (e.g. in public, or having name listed on website) benefits? Finally, would they respond differently to different types of charitable 
appeals? We would expect that they would be more likely to donate when the appeal was framed in terms of how it could benefit themselves rather than others (Willer, Wimer, \& Owens, 2015).

\section{Organizational citizenship behaviors}

Organizational citizenship behavior is prosocial behavior in the workplace that surpasses organizational requirements, such as staying late, helping coworkers, and being actively involved (Organ, 1988). Fewer studies investigate the relationship between narcissism and organizational citizenship behavior, compared to those investigating counterproductive work behavior.

Overall, narcissistic individuals perform fewer organizational citizenship behaviors (Judge, LePine, \& Rich, 2006; Min, 2013; Qureshi, Ashfaq, ul Hassan, \& Imdadullah, 2015; Yildiz \& Öncer, 2012), perhaps because they score lower in organizational trust (Yildiz \& Öncer, 2012). Yet, there is a disconnect between self-ratings versus objective ratings. One study found that supervisors rated narcissistic people as less likely to perform organizational citizenship behaviors, while narcissistic people self-reported being more likely to perform them (Judge et al, 2006).

In addition, the relationship between narcissism and organizational citizenship behaviors may depend upon impression management motives (Qureshi et al., 2015). For instance, one study found that when impression management motives were salient, the negative relationship between narcissism and organizational citizenship behaviors became positive (Qureshi et al., 2015). In other words, in line with the Extended Agency Model, narcissistic employees may perform organizational citizenship behaviors to make a favorable impression in the workplace.

\section{Discrepancies between self-reported and observer-reported prosocial behavior}

Some research examines the relationship between narcissism and combined measures of formal and informal prosocial behaviors. Most of these studies find that narcissism is associated with more self-reported prosocial behavior (Barry, Lui, \& Anderson, 2017; Kauten \& Barry, 2014, 2016; Konrath et al., 2016; Zuo, Wang, Xu, Wang, \& Zhao, 2016). However, one study finds the opposite pattern (Naderi \& Strutton, 2014), and another study finds no association (Jonason, Li, \& Teicher, 2010).

Yet in peer-report studies, narcissism is uncorrelated with prosocial behavior (Barry et al., 2017; Kauten \& Barry, 2014, 2016), which suggests a self-enhancement bias. To further complicate the picture, the parents of more narcissistic children report that they engage in more prosocial behavior (Kauten \& Barry, 2016). Future research should try to reconcile these inconsistent findings by conducting additional research or a meta-analytic integration.

\section{Informal prosocial behaviors}

Informal prosocial behaviors occur outside of organizational contexts, within other daily life settings. Overall, narcissistic people tend to behave less prosocially in interactions with strangers. For example, in a series of hypothetical decisions, narcissistic people allocated more money to themselves, and less to others (Jonason et al., 2010). In a dictator game using real money, narcissistic people gave less money, even when others could punish such ungenerous behavior (Böckler, Sharifi, Kanske, Dziobek, \& Singer, 2017). Narcissism is also associated with fewer pro-environmental behaviors and values (Naderi \& Strutton, 2014), and taking more natural resources in commons dilemma games (Brunell et al., 2013; Campbell, Bush, Brunell, \& Shelton, 2005). However, one study found no relationship between narcissism and the willingness to help by participating in future studies (Giacomin \& Jordan, 2015).

There is very little research on narcissism and prosocial behavior with friends, coworkers, romantic partners, and relatives. One study examined why narcissistic people give gifts in romantic relationships (Hyun, Park, \& Park, 2016), uncovering three key motivations: 
intrinsic (e.g. "Because I love my partner,"), maintenance (e.g. "Because I want my partner to treat me well,") and power (e.g. "Because I want to impress others.") This study found that there was no relationship between narcissism and intrinsically motivated giving, but that narcissistic people give gifts in order to maintain their relationships and to impress others. Another study found that more narcissistically exploitative people felt less obligation to return favors to others who had helped them in the past (Brunell et al., 2013). Taken together, these studies confirm the Extended Agency Model by finding that communal concerns are not very motivating to narcissistic people when giving to known others.

Situational factors affect the link between narcissism and prosocial behavior

The relationship between narcissism and prosocial behavior may depend upon situational factors. For example, the Prosocial Tendencies Scale (Carlo \& Randall, 2002) assesses selfreported tendencies to help in a variety of different contexts, such as in public, anonymously, when asked, in emotional situations, in dire situations, and for opportunistic reasons (i.e. to receive something in return). In line with the Extended Agency Model, narcissism is consistently associated with performing prosocial behaviors in public (Anderson \& Costello, 2009; EberlyLewis \& Coetzee, 2015; Konrath et al., 2016; Moran, 2016), and it is also associated with more opportunistic helping (Eberly-Lewis \& Coetzee, 2015; Konrath et al., 2016). Yet, narcissism is unrelated to helping anonymously, in response to direct requests, in emotional situations, or when in dire need.

Some studies directly manipulate situational variables to examine how these factors might influence the relationship between narcissism and prosocial outcomes. For example, one study examined whether two factors differentially affected the relationship between narcissism and empathic responses after a stranger experienced a breakup (Hepper et al., 2014). Researchers varied the severity of the person's need (either mild or severe) and the extent to which the situation was in the person's control (high or low control). As would be expected from prior research (Hepper et al., 2014; Watson et al., 1984; Zhou, Zhou, \& Zhang, 2010), narcissists had less empathic responses overall. However, this effect was especially strong in situations of mild need that were in the person's control. Perhaps narcissistic people see these people as less deserving of empathy, either because of low perceived need, or because of high perceived blame.

Another study examined whether narcissistic people could increase their empathic responding when instructed to do so (Hepper et al., 2014). Less narcissistic people felt empathy for a victim of domestic violence, whether or not they were asked to imagine her perspective. However, more narcissistic people only reported feeling empathy for her when they were asked to imagine her perspective. This implies that empathy does not come naturally for more narcissistic people, which might partially explain why their prosocial behavior is not typically driven by altruism. However, it is possible for them to empathize when directly asked.

In addition, narcissistic people seem to differentially respond to the degree of social pressure within a situation (Lannin, Guyll, Krizan, Madon, \& Cornish, 2014). More narcissistic people are less likely to help when directly asked (high social pressure), perhaps as a show of interpersonal domination. However, narcissism is unrelated to the tendency to help when under low social pressure. Although this may seem inconsistent with research finding that narcissism is associated with increased public helping, there is a difference between helping when someone is watching and helping when someone has asked. Future research should attempt to disentangle these results by examining how narcissistic people behave when being observed versus when being directly asked to help.

\section{Different types of narcissism}


Although this chapter focuses on grandiose (or overt) narcissism, other types of narcissism have received less attention in this literature.

\section{Communal narcissism}

Both grandiose and communal narcissists are motivated by power, self-esteem, and entitlement (Gebauer, Sedikides, Verplanken, \& Maio, 2012). However, communal narcissists have inflated views of their communal capacities, for example, seeing themselves as being the most helpful or caring person. Very little research focuses on communal narcissism and prosocial behavior. One study found that communal narcissists saw themselves as being helpful, warm, and trustworthy, but peers rated them lower on these attributes (Gebauer et al, 2012). Another found that communal narcissistic adolescents self-reported more anonymous prosocial behaviors, but not more public prosocial behaviors (Moran, 2016). Thus, in their self-reported behaviors at least, they appear to be more communal. However, the relationship between communal narcissism and prosocial behavior depends upon whether their need for power has been satisfied (Giacomin \& Jordan, 2015). Communal narcissists are actually less likely to help when their power and status feels secure. However, they are more likely to help when their power and status feels insecure.

\section{Vulnerable / covert narcissism}

Both grandiose and vulnerable (or covert) narcissists have high self-focus, and a need for admiration, however, vulnerable narcissists experience feelings of insecurity, contingent selfesteem, and worries about evaluation (Miller et al., 2011; Wink, 1991). The research findings on vulnerable narcissism and prosocial behavior are mixed. Some studies find that vulnerable narcissists are more prosocial (Barry et al., 2017), others find the opposite (Min, 2013; Zhou et al., 2010), and others find no relationship, whether helping in private or public (Kauten \& Barry, 2016; Moran, 2016), or when rated by observers (Barry et al., 2017; Kauten \& Barry, 2016). Clearly, more research is needed, but one study demonstrates how social pressure may matter. Vulnerable narcissists are less likely to help when under low social pressure (Lannin et al., 2014). However, when directly asked (high social pressure), there is no relationship between vulnerable narcissism and helping. Perhaps vulnerable narcissists feel uncomfortable directly refusing to help, but are okay with saying no in less direct situations.

\section{Summary}

Prior research suggests that (grandiose) narcissistic people are less likely to self-enhance on communal aspects of the self, compared to agentic ones (Campbell, Rudich, \& Sedikides, 2002; Paulhus \& John, 1998). However, in our review, we found that narcissistic people selfreported more prosocial behavior, while actually behaving less prosocially. We also find that peers do not see them as especially prosocial. So narcissistic people may be motivated to exaggerate their prosociality at times, a question that warrants further understanding. However, in line with the Extended Agency Model, narcissistic people do not report having purely altruistic reasons for giving and helping. Instead, research supports the idea that narcissistic people are prosocial in a strategic way: they are more likely to help in public or in order to receive some sort of benefit or reward, and they are less likely to volunteer for altruistic reasons. Research has also uncovered several relevant situational variables that influence the relationship between narcissism and prosocial behavior. In terms of other types of narcissism, more research is needed to better understand why, and under which conditions, communal and vulnerable narcissists behave more prosocially.

\section{Future directions}


Future research needs a more systematic approach that identifies situations in which narcissistic people are more or less likely to behave prosocially. Since the majority of research to date is on American adolescents and college students, this work should also be extended to broader populations. We recommend that scholars be guided by the Extended Agency Model and in particular, our application of that model in terms of the salience of the costs and benefits of prosocial behavior among narcissistic people.

To date, most research on this topic is correlational, which is not surprising given that narcissism is a trait. However, it is currently unknown how narcissism causally influences prosocial behavior. Thus, we recommend experiments that manipulate state narcissism levels (i.e. temporary self-focused states) to determine how narcissism affects prosocial behaviors across different situations. Related to this, some of the best studies to date vary situational variables and examine how narcissistic people react (e.g. Hepper et al, 2014). We recommend that future researchers continue to do so in order to determine key precipitating conditions for prosocial behavior among narcissistic people. It might be fruitful to directly examine to what extent narcissistic people rationally attend to the costs and benefits of prosocial behavior, versus taking a more intuitive, automatic approach to helping others (Zaki \& Mitchell, 2013).

The literature currently includes wide coverage of different types of prosocial behaviors (McGuire, 1994; Pearce \& Amato, 1980; Smithson \& Amato, 1982). However, the majority of the research involves recipients who are strangers, rather than known others. Among strangers, there is very limited research on the topics of charitable donations and more serious helping (e.g. emergency). Among known others, there is no known research on the topic of narcissism and more intensive caregiving behaviors, either with loved ones (e.g. caring for infants or sick relatives) or with strangers (e.g. providing care as part of one's profession).

Research on narcissism and prosocial behavior is in its early stages, with many exciting potential future directions. For now, based on the results of this review, we would advise people that they should pay attention to narcissists' actions, rather than their words, and that when narcissistic people do behave prosocially, it might be judicious to question their motives. 


\section{References}

Anderson, K., \& Costello, P. (2009). Relationships between prosocial behavior, spirituality, narcissism, and satisfaction with life. Journal of Gustavus Undergraduate pshychology, 5.

Barry, C. T., Lui, J. H., \& Anderson, A. C. (2017). Adolescent narcissism, aggression, and prosocial behavior: the relevance of socially desirable responding. Journal of Personality Assessment, 99(1), 46-55.

Batson, C. D. (2011). Altruism in humans: Oxford University Press.

Batson, C. D., \& Powell, A. (2003). Altruism and prosocial behavior. In T. Millon \& M. Lerner (Eds.), Handbook of Psychology. Personality and Social Psychology (Vol. Vol. 5). Hoboken, NJ: John Wiley \& Sons, Inc.

Böckler, A., Sharifi, M., Kanske, P., Dziobek, I., \& Singer, T. (2017). Social decision making in narcissism: Reduced generosity and increased retaliation are driven by alterations in perspective-taking and anger. Personality and Individual Differences, 104, 1-7.

Brunell, A. B., Davis, M. S., Schley, D. R., Eng, A. L., van Dulmen, M. H. M., Wester, K. L., \& Flannery, D. J. (2013). A new measure of interpersonal exploitativeness. Frontiers in psychology, 4. doi:299

10.3389/fpsyg.2013.00299

Brunell, A. B., Tumblin, L., \& Buelow, M. T. (2014). Narcissism and the Motivation to Engage in Volunteerism. Current Psychology, 33(3), 365-376.

Bushman, B. J., \& Baumeister, R. F. (1998). Threatened Egotism, Narcissism, Self-Esteem, and Direct and Displaced Aggression: Does Self-Love or Self-Hate Lead to Violence? Journal of Personality and Social Psychology, 75(1), 219-229.

Campbell, W. K., Bush, C. P., Brunell, A. B., \& Shelton, J. (2005). Understanding the Social Costs of Narcissism: The Case of the Tragedy of the Commons. Personality and Social Psychology Bulletin, 31(10), 1358-1368. doi:10.1177/0146167205274855

Campbell, W. K., \& Foster, C. A. (2002). Narcissism and Commitment in Romantic Relationships: An Investment Model Analysis. Personality and Social Psychology Bulletin, 28(4), 484-495. doi:10.1177/0146167202287006

Campbell, W. K., Rudich, E. A., \& Sedikides, C. (2002). Narcissism, Self-Esteem, and the Positivity of Self-Views: Two Portraits of Self-Love. Personality and Social Psychology Bulletin, 28(3), 358-368. doi:10.1177/0146167202286007

Carlo, G., \& Randall, B. A. (2002). The development of a measure of prosocial behaviors for late adolescents. Journal of youth and adolescence, 31(1), 31-44.

Carrier, J. (1991). Gifts, commodities, and social relations: A Maussian view of exchange. Paper presented at the Sociological forum.

Clary, E. G., \& Snyder, M. (1999). The Motivations to Volunteer. Current Directions in Psychological Science, 8(5), 156-159. doi:10.1111/1467-8721.00037

Clary, E. G., Snyder, M., Ridge, R. D., Copeland, J., Stukas, A. A., Haugen, J., \& Miene, P. (1998). Understanding and Assessing the Motivations of Volunteers: A Functional Approach. Journal of Personality and Social Psychology, 74(6), 1516-1530.

Corporation for National \& Community Service. (2017). Information on volunteering and civic engagement. Retrieved from http:/www. volunteeringinamerica.gov/

Eberly-Lewis, M. B., \& Coetzee, T. M. (2015). Dimensionality in adolescent prosocial tendencies: Individual differences in serving others versus serving the self. Personality and Individual Differences, 82, 1-6. 
Fengqin, D., \& Zhaohui, L. (2016). Association between empathy and prosocial behavior: A systematic review and meta-analysis. Advances in Psychological Science, 24(8), 11591174.

Gebauer, J. E., Sedikides, C., Verplanken, B., \& Maio, G. R. (2012). Communal narcissism. Journal of Personality and Social Psychology, 103(5), 854.

Giacomin, M., \& Jordan, C. H. (2015). Validating power makes communal narcissists less communal. Self and Identity, 14(5), 583-601.

Hepper, E. G., Hart, C. M., \& Sedikides, C. (2014). Moving Narcissus: Can Narcissists Be Empathic? Personality and Social Psychology Bulletin, 40(9), 1079-1091. doi:10.1177/0146167214535812

Hyun, N. K., Park, Y., \& Park, S. W. (2016). Narcissism and gift giving: Not every gift is for others. Personality and Individual Differences, 96, 47-51.

Jonason, P. K., Li, N. P., \& Teicher, E. A. (2010). Who is James Bond? The Dark Triad as an agentic social style. Individual Differences Research, 8(2), 111.

Judge, T. A., LePine, J. A., \& Rich, B. L. (2006). Loving yourself abundantly: Relationship of the narcissistic personality to self-and other perceptions of workplace deviance, leadership, and task and contextual performance. Journal of Applied Psychology, 91(4), 762-775.

Kauten, R., \& Barry, C. T. (2014). Do you think I'm as kind as I do? The relation of adolescent narcissism with self-and peer-perceptions of prosocial and aggressive behavior. Personality and Individual Differences, 61, 69-73.

Kauten, R., \& Barry, C. T. (2016). Adolescent narcissism and its association with different indices of prosocial behavior. Journal of Research in Personality, 60, 36-45.

Konrath, S., Bushman, B., \& Campbell, W. K. (2006). Attenuating the link between threatened egotism and aggression. Psychological Science, 17(11), 995-1001. doi:PSCI1818 [pii]10.1111/j.1467-9280.2006.01818.x

Konrath, S., Ho, M.-H., \& Zarins, S. (2016). The strategic helper: Narcissism and prosocial motives and behaviors. Current Psychology, 1-13.

Kristofferson, K., White, K., \& Peloza, J. (2014). The nature of slacktivism: How the social observability of an initial act of token support affects subsequent prosocial action. Journal of Consumer Research, 40(6), 1149-1166.

Lannin, D. G., Guyll, M., Krizan, Z., Madon, S., \& Cornish, M. (2014). When are grandiose and vulnerable narcissists least helpful? Personality and Individual Differences, 56, 127-132.

McGuire, A. M. (1994). Helping behaviors in the natural environment: Dimensions and correlates of helping. Personality and Social Psychology Bulletin, 20(1), 45-56.

Miller, J. D., \& Campbell, W. K. (2008). Comparing Clinical and Social - Personality Conceptualizations of Narcissism. Journal of Personality, 76(3), 449-476.

Miller, J. D., Hoffman, B. J., Gaughan, E. T., Gentile, B., Maples, J., \& Keith Campbell, W. (2011). Grandiose and vulnerable narcissism: A nomological network analysis. Journal of Personality, 79(5), 1013-1042.

Min, H. Y. (2013). The Relationship Between Self-Differentiation and Covert Narcissism in Terms of Teachers' Organization Citizenship Behavior in Childcare Centers. Korean Journal of Child Studies, 34(5), 115-126.

Moran, E. V. (2016). The Relation of Adolescent Narcissism and Prosocial Behavior with Cooperative and Competitive Attitudes. Honors thesis, The University of Southern Mississippi. 
Naderi, I., \& Strutton, D. (2014). Can normal narcissism be managed to promote green product purchases? Investigating a counterintuitive proposition. Journal of Applied Social Psychology, 44(5), 375-391. doi:10.1111/jasp.12230

Newman, G. E., \& Shen, Y. J. (2012). The counterintuitive effects of thank-you gifts on charitable giving. Journal of economic psychology, 33(5), 973-983.

O'Brien, J. (2017). Giving USA: 2015 Was America's Most-Generous Year Ever. https://givingusa.org/giving-usa-2016/.

Organ, D. W. (1988). Organizational citizenship behavior: The good soldier syndrome: Lexington Books/DC Heath and Com.

Paulhus, D. (1998). Interpersonal and Intrapsychic Adaptiveness of Trait Self-Enhancement: A Mixed Blessing? Journal of Personality and Social Psychology, 74(5), 1197-1208.

Paulhus, D., \& John, O. P. (1998). Egoistic and moralistic biases in self - perception: The interplay of self - deceptive styles with basic traits and motives. Journal of Personality, 66(6), 1025-1060.

Pearce, P. L., \& Amato, P. R. (1980). A taxonomy of helping: A multidimensional scaling analysis. Social psychology quarterly, 363-371.

Qureshi, S. U., Ashfaq, J., ul Hassan, M., \& Imdadullah, M. (2015). Impact of Extroversion and Narcissism on in Role and Extra Role Performance: Moderating Role of Impression Management Motives. Pakistan Journal of Commerce and Social Sciences, 9(1), 96-119.

Smithson, M., \& Amato, P. (1982). An unstudied region of helping: An extension of the PearceAmato cognitive taxonomy. Social psychology quarterly, 67-76.

Watson, P., Grisham, S., Trotter, M., \& Biderman, M. (1984). Narcissism and empathy: validity evidence for the Narcissistic Personality Inventory. Journal of Personality Assessment, 48(3), 301-305.

Willer, R., Wimer, C., \& Owens, L. A. (2015). What drives the gender gap in charitable giving? Lower empathy leads men to give less to poverty relief. Social science research, 52, 8398.

Wink, P. (1991). Two faces of narcissism. Journal of Personality and Social Psychology, 61(4), 590-597.

Yildiz, M. L., \& Öncer, A. Z. (2012). Narcissism as a Moderator of the Relationship between Organizational Trust and Organizational Citizenship Behaviour. International Journal of Business and Social Science, 3(21).

Zaki, J., \& Mitchell, J. P. (2013). Intuitive prosociality. Current Directions in Psychological Science, 22(6), 466-470.

Zhou, H., Zhou, H., \& Zhang, B. (2010). Relationships among narcissism, empathy, and prosocial behaviours. Chinese Journal of Clinical Psychology, 18(2), 228-231.

Zuo, S., Wang, F., Xu, Y., Wang, F., \& Zhao, X. (2016). The fragile but bright facet in the Dark Gem: Narcissism positively predicts personal morality when individual's self-esteem is at low level. Personality and Individual Differences, 97, 272-276. 